\title{
Sustainable economic development at the meso level: factors and ratings
}

\author{
Kirill Kulakov², Svetlana Belyaeva ${ }^{1,{ }^{*}}$, Oksana Belyantseva ${ }^{1}$ and Anetta Gamisoniya ${ }^{3}$ \\ ${ }^{1}$ Voronezh State Technical University, Moscow Avenue, 14, Voronezh, 394026, Russia \\ ${ }^{2}$ Moscow State University of Civil Engineering, Yaroslavskoye shosse, 26, Moscow, 129337, Russia \\ ${ }^{3}$ Abkhazian State University, Universitetskaya Avenue, 1, Sukhum, 384904, Abkhazia
}

\begin{abstract}
Existing approaches to assessing the sustainability of an economic system that is in a state of reform or in a transition period (industry, region) have some disadvantages. Some approaches can be applied only to static systems or systems with a stable structure, while others do not have predictive properties. Therefore, there is a need to develop a methodology that can provide a more accurate conclusion about the sustainability and prospects of an industry or region undergoing organizational reform. The authors proposed methodological approaches to assessing the level of stability of the functioning of the region and the industry in terms of deregulation, based on existing ratings, differing in the use of econometric methods.
\end{abstract}

\section{Introduction}

One of the main components of sustainable economic development is the provision of an attractive investment climate at the federal and regional levels, which in itself is the foundation for successful development. In order to optimize the mechanisms of sustainable development, we consider it expedient to conduct an econometric analysis of existing ratings of regions, as well as sectors that determine the dynamics of GDP [1]. Based on the analysis of models, it is necessary to identify the significant factors on which ratings are based. In fact, based on the results of the analysis, one can answer the question of what is included in the concept of the region's investment climate [2] and the sustainability of the industry [3].

The primary task of federal and municipal authorities is to analyze and assess the investment potential of the regions in order to identify regions that require targeted federal support. Ranking of regions by the amount of investment potential is necessary for investors in order to determine the directions for more effective investment of funds. In addition, such an analysis will identify the advantages and disadvantages of managing a particular region, as well as the direction of a sound regional policy.

For the Russian Federation, in which there are a number of methods for rating regions [4-6], and, however, there is no single common regulatory framework for calculating [7], on the one hand, it is necessary to systematize existing methods and identify key rating

\footnotetext{
*Corresponding author: belyaeva-sv@mail.ru
} 
factors, on the other hand, it is advisable to develop and the introduction of a single common methodology to increase the objectivity of the results. For the Republic of Abkhazia, where the practice of the rating and its methodological justification are not yet sufficiently developed, the issues of identifying significant factors of investment attractiveness at the meso level are extremely relevant and necessary for the development of a strategy for sustainable development and tactics for its implementation.

The rating of industries in terms of the level of sustainability in each country and region creates a basis for a sound fiscal and tax policy aimed at creating a trend for intensive economic growth and creating drivers for sustainable development of the country's economy as a whole.

\section{Materials and methods}

Turning to further consideration of the experience of constructing integral socio-economic indicators, it should be noted first of all that attempts to construct and use them in analytical work have been undertaken and are being undertaken a great deal (both in Russia and abroad) and on this subject there is a significant number publications. An extensive bibliography on the problem is contained, for example, in [8]. It is not possible to analyze them more or less in detail in this paper. We will dwell on the consideration of those studies known to us in this field that have been carried out in our country in recent years and either directly touch upon various aspects of assessing the state of regions and sectors of the Russian economy, or the methodical methods of constructing which can be used to solve this problem.

One of the objectives of the study is to econometrically analyze existing ratings of regions, build a model for these ratings, and build model ratings based on the rankings of proposals by experts, based on investment risk and investment potential.

For a detailed study, we selected two ratings of the region's investment attractiveness: rating based on the rank of potential and risk rank proposed by RA Expert. These ratings contain enough data for economic analysis. 


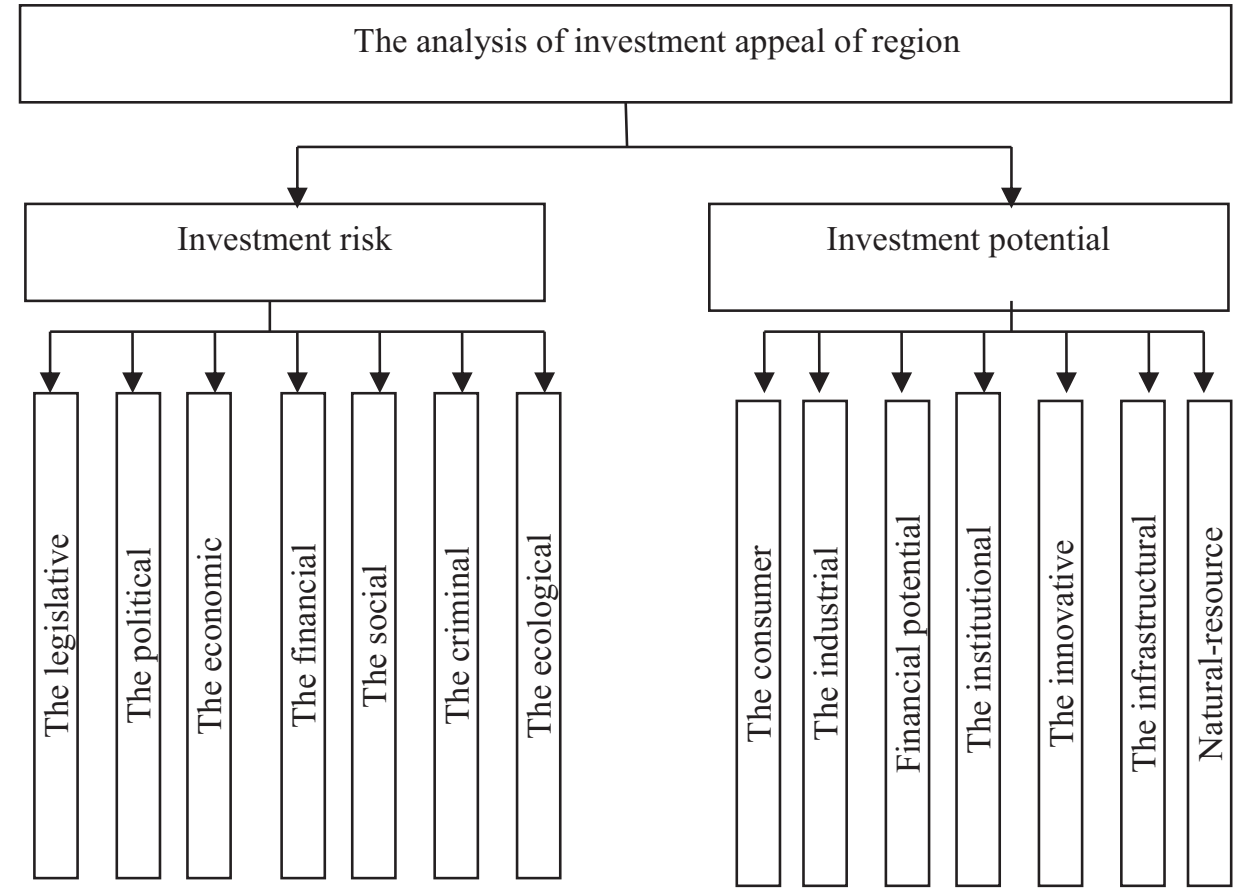

Fig. 1. Analysis of the investment attractiveness of the region according to the methodology of RA "Expert".

Since the rating is a qualitative ordinal variety, the natural choice for studying the ratings is the multiple choice models [9].

An analysis of the pair correlation of the ratings of the regional estimates on the basis of the rank of risk and the rank of the potential will be made using the Spearman coefficient. We determine the degree of influence of each factor on the result. Factor loads are calculated on the basis of the correlation coefficient of ranks, which measures the tightness of the connection of factors.

Data on factorial loads allow us to formulate conclusions about the relative weight of an individual trait in the structure of the resulting factor. In turn, data on factor weights determine the ranking of objects for each factor. The coefficient of determination is adopted for the numerical characteristic of the factor load.

Consequently, the objective function can be represented in an additive form:

$$
F=a Q_{Z}+b Q_{P}+c Q_{E}+d Q_{F}+e Q_{S}+f Q_{K}+h Q_{E K}
$$

$Q z$ - factor of an optimum or a rank of legislative risk; $Q p$ - factor of an optimum of political risk; $Q e$ - factor of an optimum of economic risk; $Q f$ - factor of an optimum of financial risk; $Q s$ - Factor of an optimum of social risk; $Q k$ - Factor of an optimum of criminal risk; Qek - factor of an optimum of ecological risk; $a, b, c, d, e, f, h$ - measures of influence of defining factors on productive, or sizes of factorial loadings.

$$
F=a Q_{T}+b Q_{P}+c Q_{E}+d Q_{F}+e Q_{I}+f Q_{K}+h Q_{I N}+g Q_{P R}
$$

$Q t$ - factor of an optimum or a rank of labour potential; $Q p$ - factor of an optimum of consumer potential; $Q e$ - factor of an optimum of industrial potential; $Q f$ - factor of an optimum of financial potential; $Q i$ - Factor of an optimum of institutional potential; $Q k$ Factor of an optimum of innovative potential; Qin - factor of an optimum of infrastructural 
potential; $Q p r$ - factor of an optimum of prirodno-resource potential; $a, b, c, d, e, f, h, g$ measures of influence of defining factors on productive, or sizes of factorial loadings.

According to the methodology of RA "Expert", the investment attractiveness of the country and regions is determined by integral indicators of investment potential and risk. We have identified key factors of investment potential and risk.

Table 1. Determination of key factors of investment attractiveness based on the rank of risk.

\begin{tabular}{|c|c|c|c|}
\hline Indicator & $\begin{array}{c}\text { Factor of correlation of } \\
\text { Spearmen's }\end{array}$ & $\begin{array}{c}\text { Determination } \\
\text { factor }\end{array}$ & $\begin{array}{c}\text { The rating of a rank } \\
\text { of risk }\end{array}$ \\
\hline Legislative risk & $\mathbf{0 , 6 1 3}$ & $\mathbf{0 , 3 7 5}$ & $\mathbf{3}$ \\
\hline Political risk & 0,063 & 0,004 & 7 \\
\hline Economic risk & $\mathbf{0 , 7 7 4}$ & $\mathbf{0 , 6 0 0}$ & $\mathbf{1}$ \\
\hline Financial risk & $\mathbf{0 , 6 8 8}$ & $\mathbf{0 , 4 7 4}$ & $\mathbf{2}$ \\
\hline Social risk & 0,578 & 0,346 & 5 \\
\hline Criminal risk & 0,610 & 0,373 & 4 \\
\hline Ecological risk & $-0,076$ & 0,006 & 6 \\
\hline
\end{tabular}

Table 2. Rating evaluation of the investment attractiveness of the country and the region on the basis of the rank of investment potential.

\begin{tabular}{|c|c|c|c|}
\hline Indicator & $\begin{array}{c}\text { Factor of correlation of } \\
\text { Spearmen's }\end{array}$ & $\begin{array}{c}\text { Determination } \\
\text { factor }\end{array}$ & $\begin{array}{c}\text { The rating of a rank } \\
\text { of risk }\end{array}$ \\
\hline Labour potential & 0,922 & 0,851 & 5 \\
\hline Consumer potential & $\mathbf{0 , 9 5 7}$ & $\mathbf{0 , 9 1 6}$ & $\mathbf{3}$ \\
\hline Industrial potential & $\mathbf{0 , 9 6 0}$ & $\mathbf{0 , 9 2 2}$ & $\mathbf{2}$ \\
\hline Financial potential & $\mathbf{0 , 9 6 2}$ & $\mathbf{0 , 9 2 5}$ & $\mathbf{1}$ \\
\hline Institutional potential & 0,938 & 0,888 & 4 \\
\hline Innovative potential & 0,882 & 0,778 & 6 \\
\hline Infrastructural \\
potential
\end{tabular}

As a measure of the consistency of the assessment, we use the coefficient of concordance (consistency) of Kendall's ranks (Tab.3)

Table 3. The resulting Kendall coefficient calculation table.

\begin{tabular}{|l|l|}
\hline Risk rank & \\
\hline Average rank, where $\mathrm{n}=89, \mathrm{~m}=7$ & 315 \\
\hline Factor of concordance & 0,254 \\
\hline $\mathrm{m}(\mathrm{n}-1)^{*} \mathrm{~W}$ & 156,45 \\
\hline Potential rank & \\
\hline Average rank, where $\mathrm{n}=89, \mathrm{~m}=8$ & 360,01 \\
\hline Factor of concordance & 0,662 \\
\hline $\mathrm{m}(\mathrm{n}-1)^{*} \mathrm{~W}$ & 466,07 \\
\hline The generalising characteristic & \\
\hline The average sum of ranks of ratings $\mathrm{m}=2, \mathrm{n}=88$ & 89,114 \\
\hline Factor of concordance & 0,74 \\
\hline $\mathrm{m}(\mathrm{n}-1) * \mathrm{~W}$ & 128,76 \\
\hline
\end{tabular}

After the calculations, the objective functions will have the following form:

The objective function of the risk of the investment policy of the region:

$$
F=0,287 Q_{Z}+0,004 Q_{P}+0,375 Q_{E}+0,474 Q_{F}+0,600 Q_{S}+0,373 Q_{K}+0,006 Q_{E K}
$$

The objective function of the investment policy potential of the region 


$$
F=0,851 Q_{T}+0,916 Q_{P}+0,922 Q_{E}+0,925 Q_{F}+0,888 Q_{I}+0,778 Q_{K}+0,135 Q_{I N}+0,149 Q_{P R}
$$

In our opinion, the methodology for assessing the investment attractiveness of the region is rather laborious both from the point of view of collecting the initial statistical information and from the point of view of the analysis and calculation methodology. In addition, some of the indicators are highly correlated and therefore interdependent and replaceable. Therefore, in order to optimize the calculations for a potential investor, we consider it expedient to modify the methodology of RA Expert in the following way:

1. We propose to analyze the investment risk by three components, the tightness of which is maximized with the resulting indicator (social risk, financial risk, economic risk).

2. It is also expedient to calculate the investment potential for three main factors, which have the greatest impact on the final potential (financial potential, production potential, consumer potential).

3. It is necessary to add to the analyzed indicators the third section "Legislative and Legal Potential" (the region to which this study is directed).

Having obtained a modified methodology for assessing the investment potential of the region and making a recalculation of all indicators, we obtained the following results:

1. The results of calculating the Spearman correlation coefficient and the determination coefficient remain the same (Table 4);

Table 4. Results of calculating the risk rank and the rank of the potential, obtained by a modified procedure.

\begin{tabular}{|l|c|c|}
\hline \multicolumn{1}{|c|}{ Indicator } & $\begin{array}{c}\text { Spearmen's rank correlation } \\
\text { coefficient }\end{array}$ & Coefficient of determination \\
\hline Risk rank & & 0,6 \\
\hline Social risk & 0,774 & 0,474 \\
\hline Financial risk & 0,688 & 0,375 \\
\hline Economic risk & 0,613 & 0,925 \\
\hline Potential rank & & 0,922 \\
\hline Financial potential & 0,962 & 0,916 \\
\hline Industrial potential & 0,96 & \\
\hline Consumer potential & 0,957 & \\
\hline
\end{tabular}

2. The calculation of the concordance coefficient by components has changed, and the generalizing characteristic has remained unchanged (Table 5). This makes it possible to assume that the optimization of the method is possible, since the results of calculations are close.

Table 5. The resulting table for calculating the Kendall coefficient according to the updated methodology.

\begin{tabular}{|l|c|}
\hline Risk rank & \\
\hline Average rank, where $\mathrm{n}=89, \mathrm{~m}=7$ & 315,000 \\
\hline Factor of concordance & 0,136 \\
\hline $\mathrm{m}(\mathrm{n}-1) * \mathrm{~W}$ & 35,933 \\
\hline Potential rank & \\
\hline Average rank, where $\mathrm{n}=89, \mathrm{~m}=8$ & 135,000 \\
\hline Factor of concordance & 0,137 \\
\hline $\mathrm{m}(\mathrm{n}-1) * \mathrm{~W}$ & 36,245 \\
\hline The generalising characteristic & \\
\hline The average sum of ranks of ratings $\mathrm{m}=2, \mathrm{n}=88$ & 89,114 \\
\hline Factor of concordance & 0,740 \\
\hline $\mathrm{m}(\mathrm{n}-1) * \mathrm{~W}$ & 128,760 \\
\hline
\end{tabular}

In this case, the objective functions acquired the following form: 
Function of risk of investment policy of the region:

$$
F=0,375 Q_{E}+0,474 Q_{F}+0,600 Q_{S}
$$

Function of the investment policy potential of the region

$$
F=0,916 Q_{P}+0,922 Q_{E}+0,925 Q_{F}
$$

Function of the investment policy potential of the region

Analysis of the rank of risk and potential has shown that in the Central Federal District the discrepancy in the calculated and initial values of the potential is small, therefore the optimized factor function is reliable and is possible for application in calculating the investment attractiveness of not only the region as a whole, but also in a separate industry in particular.

\section{Results}

Based on the data obtained, we will analyze the investment attractiveness of the Central Federal District. Depending on the weight categories of the factors obtained, we calculate new data on the investment risk and the investment potential of the region.

Since the calculation of the coefficient of determination was carried out for all subjects of the Russian Federation on average, it can be concluded that the initial value of the risk rank for some regions and regions is strongly divergent from the modified value. This can be explained by the fact that in these areas, the risk components are influenced to a greater or lesser extent by the components of investment risk that were not taken into account in the modification.

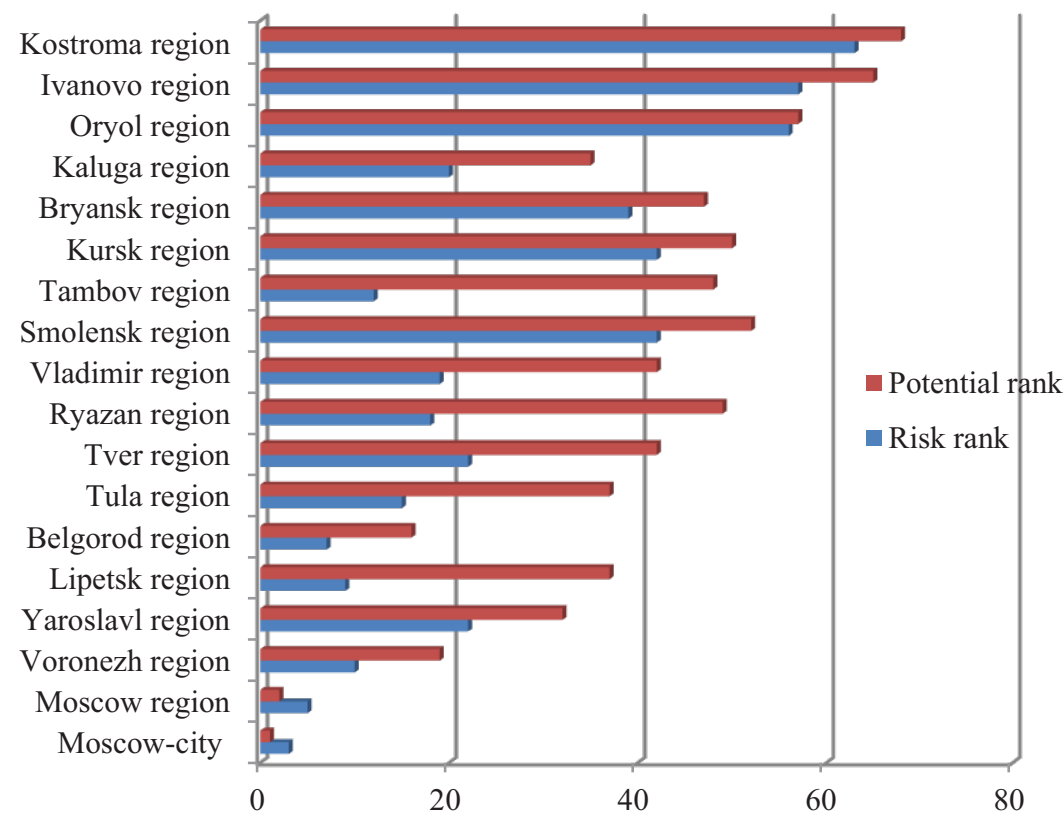

Fig. 2. Assessment of the investment potential and risk of the regions of the Central Federal District of the Russian Federation. 
Among the regions of the Central Federal District Voronezh takes the third place by the availability of investment potential and the sixteenth (from 18 regions) by the riskiness of investments in this area. As a result, the overall rank of investment attractiveness is high.

Applying the proposed methodology for assessing the investment potential and risk of the Republic of Abkhazia, in the dynamics we obtain the following values (Table 3).

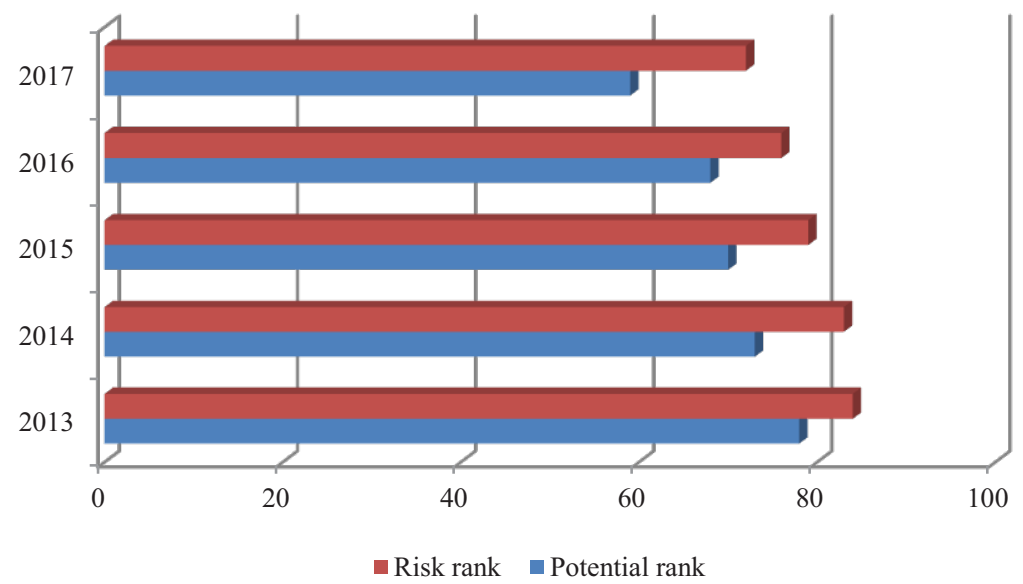

Fig. 3. Dynamics of investment potential and risk of the Republic of Abkhazia.

Applying the obtained methodology to the assessment of the stability of the industries, for modeling we grouped the most significant criteria and factors of the economic sustainability of the industry on the basis of analysis of the theory of stability assessment, data from surveys of the Federal State Statistics Service. To process the results, all evaluations are summarized in the form (Table 6).

Table 6. Assessment of the consistency of experts on scores of factors of sustainability of the industry.

\begin{tabular}{|c|c|c|c|c|c|c|c|c|c|c|c|c|}
\hline \multirow[b]{2}{*}{ Indicator } & \multicolumn{8}{|c|}{ Estimations of experts } & \multirow{2}{*}{ 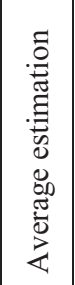 } & \multirow[b]{2}{*}{ 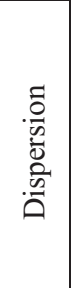 } & \multirow{2}{*}{ 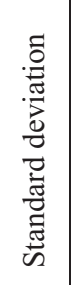 } & \multirow[b]{2}{*}{ 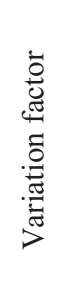 } \\
\hline & 1 & 2 & 3 & 4 & 5 & 6 & 7 & 8 & & & & \\
\hline \multicolumn{13}{|l|}{ Technological stability } \\
\hline Investments into fixed capital & 9 & 10 & 8 & 10 & 10 & 10 & 10 & 10 & 9,63 & 0,55 & 0,74 & 0,08 \\
\hline Deterioration of fixed capital & 9 & 9 & 8 & 8 & 9 & 8 & 8 & 8 & 8,38 & 0,27 & 0,52 & 0,06 \\
\hline Factor of updating of fixed capital & 7 & 8 & 7 & 8 & 7 & 8 & 8 & 8 & 7,63 & 0,27 & 0,52 & 0,07 \\
\hline Number of the workers occupied in branch & 9 & 9 & 7 & 9 & 9 & 8 & 6 & 7 & 8,00 & 1,43 & 1,20 & 0,15 \\
\hline Turnover of staff & 8 & 7 & 6 & 8 & 8 & 8 & 8 & 9 & 7,75 & 0,79 & 0,89 & 0,11 \\
\hline Innovations & 9 & 7 & 6 & 7 & 7 & 6 & 9 & 10 & 7,63 & 2,27 & 1,51 & 0,20 \\
\hline \multicolumn{13}{|l|}{ Economic stability } \\
\hline Rate of branch growth & 8 & 9 & 8 & 9 & 9 & 8 & 7 & 8 & 8,25 & 0,50 & 0,71 & 0,09 \\
\hline
\end{tabular}




\begin{tabular}{|c|c|c|c|c|c|c|c|c|c|c|c|c|}
\hline ict & 8 & 1 & & & 8 & & & & 9,00 & 0,57 & 0,76 & 0,08 \\
\hline Stability of branch to economic recession & 5 & 7 & & & 7 & & & & 6,25 & 0,79 & 0,89 & 0,14 \\
\hline The branch indicator of profitability & 8 & 7 & 5 & 9 & 10 & 8 & 8 & 8 & 7,88 & 2,13 & 1,46 & 0,15 \\
\hline Turn of the organisations of branch & 8 & 8 & 9 & 8 & 7 & 8 & 9 & & 8,38 & 0,84 & 0,92 & 0,1 \\
\hline Competition level in branch & 9 & 5 & 7 & 7 & 5 & 8 & 10 & 8 & 7,38 & 3,13 & 1,77 & 0,24 \\
\hline Stability of the prices for branch production & 5 & 9 & 6 & 9 & 9 & 8 & 9 & 9 & 8,00 & 2,57 & 1,60 & 0 , \\
\hline Level of dependence on availability of credits & 8 & 8 & 5 & 8 & 9 & 8 & 9 & 8 & 7,88 & 1,55 & 1,25 & 0 , \\
\hline Level of a demand in th & 8 & 9 & 8 & 9 & 10 & 7 & 10 & 8 & 8,63 & 1,13 & 1,06 & 0,1 \\
\hline Share of the profitable organisations in branch & 8 & 8 & 9 & 8 & 8 & 9 & 9 & 9 & 8,50 & 0,29 & 0,53 & 0 , \\
\hline \multicolumn{13}{|l|}{ Organizational stability } \\
\hline Level o & 10 & 10 & 7 & 9 & 9 & 10 & 1( & & 9,25 & 1,07 & 1,04 & 0 , \\
\hline Social role of branch & 8 & 6 & 5 & 8 & 6 & 10 & 9 & 8 & 7,50 & 2,86 & 1,69 & 0 , \\
\hline Financial working conditions of branch & 8 & 6 & 5 & 7 & 4 & 10 & 9 & 7 & 7,00 & 4,00 & 2,00 & 0 \\
\hline Quantity of the countries-importers & 8 & 5 & & 4 & 4 & 5 & 7 & 6 & 5,63 & 1,98 & 1,41 & 0,25 \\
\hline "Price- & 6 & 5 & 6 & 5 & 5 & 6 & 6 & 5 & 5,50 & 0,29 & 0,53 & 0 \\
\hline $\begin{array}{l}\text { Preferential tax/customs mode } \\
\text { base of branch }\end{array}$ & 7 & 7 & 7 & 6 & 5 & 6 & 7 & 6 & 6,38 & 0,55 & 0,74 & 0 , \\
\hline The state credit & 8 & 4 & 5 & 5 & 4 & 6 & 8 & 6 & 5,75 & 2,50 & 1,58 & 0, \\
\hline The changes of the legislation directed on stabilisation & 7 & 3 & 7 & & 2 & 3 & 7 & & 4,50 & 4,57 & 2,14 & \\
\hline Completeness of standard and le & 6 & 9 & 3 & 9 & 9 & 8 & 8 & & 7,75 & 2,21 & 1,49 & 0, \\
\hline
\end{tabular}

As a result of the expert evaluation, key criteria for the sustainability of the industry were selected.

The function of the industry's sustainability, taking into account the results of the expert evaluation and the determination of the share of influence of the criteria on the integral indicator of the level of stability, can be presented in an additive form:

$$
\begin{gathered}
\mathrm{U}=0,1 \mathrm{~B}_{\mathrm{ok}}+0,09 \mathrm{~B}_{\mathrm{if}}+0,09 \mathrm{~B}_{\mathrm{cr}}+0,09 \mathrm{~B}_{\mathrm{tr}}+0,09 \mathrm{~B}_{\mathrm{vvp}} \\
+0,09 \mathrm{~B}_{\mathrm{vr}}+0,09 \mathrm{~B}_{\mathrm{d}}+0,09 \mathrm{~B}_{\mathrm{gp}}+0,1 \mathrm{~B}_{\mathrm{gk}}
\end{gathered}
$$

where U - level of stability of branch; Bok - points by criterion of volume of investments into branch fixed capital; Bif - points by criterion of degree of deterioration of fixed capital of branch; Bcr - points by criterion of number of workers of branch; Btr points by criterion of rates of branch growth; Bvvp - points by criterion of manufacture of gross national product in branch; Bvr - points by criterion of a demand of branch in the conditions of recession; $\mathrm{Bd}$ - points by criterion of a share of the profitable organisations in branch; Bgp - points by criterion of level of the state intervention in branch; Bgk - points by criterion of volume of the state credits of branch.

The level of sustainability of the branches of the national economy is shown in Figure 4. 


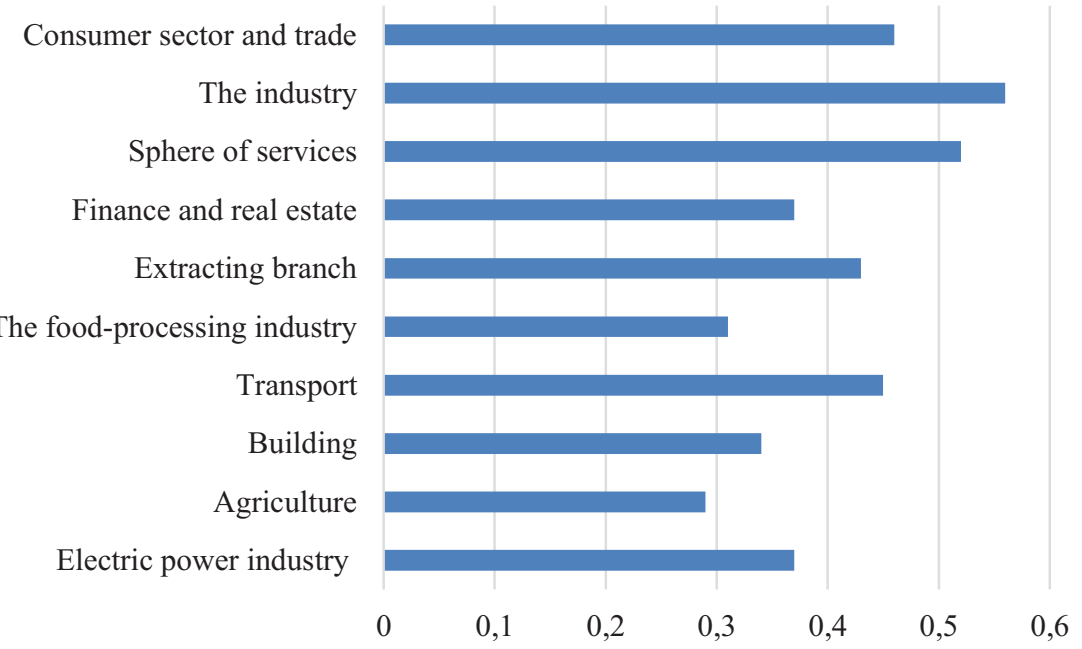

Fig. 4. The level of sustainability of the Russian economy.

A similar assessment for the sustainability of the economy of the Republic of Abkhazia is shown in Figure 5.

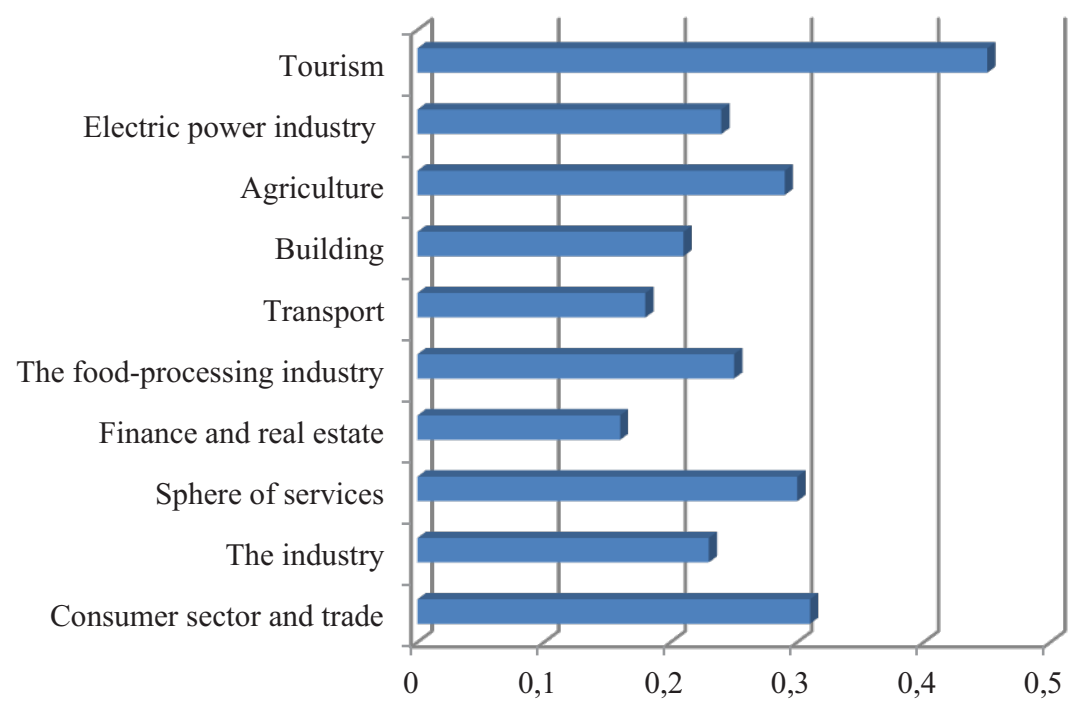

Fig. 5. The level of sustainability of the economic sectors of the Republic of Abkhazia.

As can be seen from the calculation results, the highest level of sustainability is accounted for by sectors that already have the character of drivers of sustainable development of the republic. However, the overall level of sustainability is lower than that of similar sectors of the Russian economy, which indicates the need to implement effective public policy measures in the sphere of not only spatial regulation of mesoeconomics and state zoning policy, but also in the sphere of structural transformations of the economy of the Republic of Abkhazia 


\section{Discussions}

For the investor, the most important thing is the stability of the legislative base, observance of legal norms and the possibility to ensure their enforcement. This thesis was confirmed by us by econometric analysis of the investment rating of the country and the regions of Armenia "Expert".

On the territory of most regions there is a single federal or "federal" legislative background, which is slightly modified in certain regions (subjects of the federation) under the influence of regional legislative norms that regulate investment activity only within its powers.

In addition, the legislation, as a rule, not only affects the degree of investment risk, but also regulates the investment opportunities in certain spheres or industries, determines the procedure for the use of certain factors of production - the components of the investment potential of the region.

The sustainability of the industry also depends on the degree and direction of government intervention. Therefore, the most important task of assessing the sustainability of the industry and the investment attractiveness of the region is the development of regulatory impacts and, above all, institutional foundations that affect the key sustainability factors in order to further develop positive trends and overcome the limitations of effective sustainable economic development.

\section{Conclusion}

The proposed recommendations substantiate the key criteria for sustainable development of the industry and the region, allowing monitoring and taking proactive actions to prevent the loss of sustainability.

The presented methodological recommendations provide a comprehensive accounting of quantitative and qualitative approaches to the assessment of sustainability and allow to make a rating of the branches of the national economy and regions of the country.

The task of ensuring a sufficient level of sustainability of the industry and the region is of paramount importance in the conditions of economic recovery from the crisis, when the ability of market participants to function successfully and develop under adverse economic conditions is determined.

\section{References}

1. I.V. Ilin, A. Lepekhin, A.I. Levina, O.Yu. Iliashenko, Advances in Intelligent Systems and Computing 692, 1306-1314 (2018) DOi -10.1007/978-3-319-70987-1_13

2. A. Vasilyev, Stas Marketing Partner 11, 1-18 (2008)

3. O. Ustyuzhina, S. Husainova, Vestnik Adygejskogo gosudarstvennogo universiteta, 2 (2013)

4. A. Il'yushchenko, Biznes-obrazovanie v ehkonomike znanij 1(6) (2017)

5. L. Deputatova, M. Lutchenko, Izvestiya Saratovskogo universiteta. Novaya seriya. Seriya: EHkonomika. Upravlenie. Pravo 13(2), 215-218 (2013)

6. S. Uvarova, D. Voronov, S. Erypalov, MATEC Web of Conferences 106, 08036 (2017)

7. S. Uvarova, V. Vlasenko, A. Bukreev, L. Myshovskaya, O. Kuzina, E3S Web of Conferences, 03022 (2018) 
8. V. Kankhva, MATEC Web of Conferences 106, 08022 (2017) doi: 10.1051/ matecconf/ 201710608022

9. E. Nezhnikova, Procedia Engineering, 165 (2016) doi :10.1016/j.proeng.2016.11.854 